\title{
Dietary omega-3 polyunsaturated fatty acids suppress NHE-1 upregulation in a rabbit model of volume- and pressure-overload
}

\author{
Marcel M. G. J. van Borren ${ }^{1,2}$, Hester M. den Ruijter ${ }^{1,3}$, Antonius Baartscheer ${ }^{1}$, Jan H. Ravesloot ${ }^{1}$, \\ Ruben Coronel ${ }^{1 *}$ and Arie O. Verkerk ${ }^{1}$ \\ ${ }^{1}$ Heart Failure Research Center, Academic Medical Center, University of Amsterdam, Amsterdam, Netherlands \\ ${ }^{2}$ Laboratory of Clinical Chemistry and Haematology, Jeroen Bosch Hospital, 's-Hertogenbosch, Netherlands \\ 3 Julius Center for Health Sciences and Primary Care, University Medical Center, Utrecht, Netherlands
}

\section{Edited by:}

George E. Billman, Ohio State

University, USA

\section{Reviewed by:}

Ravi C. Balijepalli, University of Wisconsin, USA

David R. Van Wagoner, Cleveland Clinic Lerner College of Medicine of

Case Western Reserve University, USA

Hugh Clements-Jewery, West Virginia School of Osteopathic Medicine, USA

\section{${ }^{*}$ Correspondence:}

Ruben Coronel, Experimental

Cardiology Group, Heart Failure Research Center, Academic Medical Center, Room K2-112, Meibergdreef 15, 1105 AZ Amsterdam, Box 22700, 1100 DE Amsterdam, Netherlands. e-mail: rubencoronel@gmail.com

\begin{abstract}
Background: Increased consumption of omega-3 polyunsaturated fatty acids ( $\omega 3$-PUFAs) from fish oil (FO) may have cardioprotective effects during ischemia/reperfusion, hypertrophy, and heart failure (HF). The cardiac $\mathrm{Na}^{+} / \mathrm{H}^{+}$-exchanger (NHE-1) is a key mediator for these detrimental cardiac conditions. Consequently, chronic NHE-1 inhibition appears to be a promising pharmacological tool for prevention and treatment. Acute application of the FO $\omega 3$-PUFAs eicosapentaenoic acid (EPA) and docosahexaenoic acid (DHA) inhibit the $\mathrm{NHE}-1$ in isolated cardiomyocytes. We studied the effects of a diet enriched with $\omega 3$-PUFAs on the NHE-1 activity in healthy rabbits and in a rabbit model of HF induced by volumeand pressure-overload. Methods: Rabbits were allocated to four groups. The first two groups consisted of healthy rabbits, which were fed either a diet containing $1.25 \%(\mathrm{w} / \mathrm{W})$

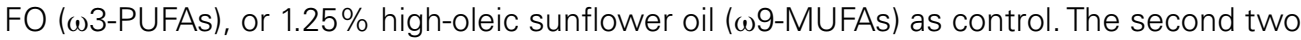
groups were also allocated to either a diet containing $\omega 3$-PUFAs or $\omega 9$-MUFAs, but underwent volume- and pressure-overload to induce HF. Ventricular myocytes were isolated by enzymatic dissociation and used for intracellular $\mathrm{pH}\left(\mathrm{pH}_{\mathrm{i}}\right)$ and patch-clamp measurements. NHE-1 activity was measured in HEPES-buffered conditions as recovery rate from acidosis due to ammonium prepulses. Results: In healthy rabbits, NHE-1 activity in $\omega 9-M U F A s$ and $\omega 3-P U F A s$ myocytes was not significantly different. Volume- and pressure-overload in rabbits increased the NHE-1 activity in $\omega 9$-MUFAs myocytes, but not in $\omega 3$-PUFAs myocytes, resulting in a significantly lower NHE-1 activity in myocytes of w3-PUFA fed HF rabbits. The susceptibility to induced delayed afterdepolarizations (DADs), a cellular mechanism of arrhythmias, was lower in myocytes of HF animals fed $\omega 3$-PUFAs compared to myocytes of $\mathrm{HF}$ animals fed $\omega 9$-MUFAs. In our rabbit HF model, the degree of hypertrophy was similar in the $\omega 3$-PUFAs group compared to the $\omega 9$-MUFAs group. Conclusion: Dietary $\omega 3$-PUFAs from FO suppress upregulation of the NHE-1 activity and lower the incidence of DADs in our rabbit model of volume- and pressure-overload.
\end{abstract}

Keywords: $\mathrm{Na}^{+} / \mathrm{H}^{+}$-exchanger, $\mathrm{pH}_{\mathrm{i}}$, fish oil, diet, heart failure, hypertrophy, arrhythmias

\section{INTRODUCTION}

Increased consumption of omega-3 polyunsaturated fatty acids ( $\omega 3$-PUFAs) from fish oil (FO) may exert beneficial effects on the heart, as evidenced by a decreased risk of ischemic heart disease, sudden cardiac death (Burr et al., 1989; GISSI-Prevenzione Investigators, 1999), and a lower incidence of heart failure (HF; Mozaffarian et al., 2005; Yamagishi et al., 2008; Levitan et al., 2009; Chen et al., 2011). Various mechanisms for the observed beneficial effects of $\omega 3$-PUFAs have been proposed, i.e., decrease in blood pressure, heart rate, and platelet aggregation, antiinflammatory (Kris-Etherton et al., 2002), and ionic remodeling resulting in a decrease of cardiac arrhythmias (den Ruijter et al., 2007; London et al., 2007), but the exact mechanisms are not fully known.
Evidence is increasing that the $\mathrm{Na}^{+} / \mathrm{H}^{+}$-exchanger isoform1 (NHE-1) plays a crucial role in ischemia/reperfusion injury, hypertrophy, and HF (for reviews, see Cingolani and Ennis, 2007; Fliegel, 2009; Vaughan-Jones et al., 2009). The NHE-1 is an integral membrane protein that extrudes one $\mathrm{H}^{+}$ion in exchange for one $\mathrm{Na}^{+}$ion in an electroneutral fashion. Its activity is high at acidic intracellular $\mathrm{pH}\left(\mathrm{pH}_{\mathrm{i}}\right)$ conditions and gradually declines to zero when its set-point $\mathrm{pH}_{\mathrm{i}}$ value, just above resting $\mathrm{pH}_{\mathrm{i}}$ value $(\sim \mathrm{pH} 7.2)$ is reached. At resting $\mathrm{pH}_{\mathrm{i}}$ acid extrusion through NHE1 activity equals acid loading activity and proton production rate, thereby maintaining $\mathrm{pH}_{\mathrm{i}}$ at neutral values. This, however, is at the expense of a continuous $\mathrm{Na}^{+}$influx. Thus, the NHE-1 has also a major role in intracellular $\mathrm{Na}^{+}\left(\left[\mathrm{Na}^{+}\right]_{\mathrm{i}}\right)$ loading (Baartscheer and van Borren, 2008; Fliegel, 2009; Vaughan-Jones et al., 2009). 
This $\left[\mathrm{Na}^{+}\right]_{\mathrm{i}}$ loading effect is of importance especially under conditions where NHE-1 activity is high such as ischemia/reperfusion (Ayoub et al., 2003; Bak and Ingwall, 2003; van Borren et al., 2004), hypertrophy, and HF (Baartscheer et al., 2003a; Chahine et al., 2005; van Borren et al., 2006; Nakamura et al., 2008). In these conditions, the $\left[\mathrm{Na}^{+}\right]_{\mathrm{i}}$ loading via the NHE-1 shifts the driving force of $\mathrm{Na}^{+} / \mathrm{Ca}^{2+}$ exchange into the direction of less forward and increased reversed modes, which consequently will elevate intracellular $\mathrm{Ca}^{2+}\left(\left[\mathrm{Ca}^{2+}\right]_{\mathrm{i}}\right)$ concentration with potentially detrimental cardiac effects. Consequently, a reduction of $\mathrm{Na}^{+}$influx via NHE-1 inhibition appears to be a promising pharmacological tool for the treatment of ischemia/reperfusion, hypertrophy, and HF (Baartscheer et al., 2005; Cingolani and Ennis, 2007).

Goel et al. (2002) have shown that acute application of the $\omega 3$ PUFA eicosapentaenoic acid (EPA) as well as docosahexaenoic acid (DHA) inhibited the NHE-1 in isolated cardiomyocytes. Considering the importance of NHE-1 in ischemia/reperfusion injury, hypertrophy, and HF, NHE-1 inhibition may be the crucial link between FO and the well-known cardioprotective effects of $\omega 3$-PUFAs. In addition, it suggests that $\omega 3$-PUFAs may be an alternative or a complementary approach to existing NHE-1 inhibiting pharmacological drugs. In the present study we assessed the effects of long term treatment with $\omega 3$-PUFAs on NHE-1 in healthy rabbits and in a rabbit model of volume- and pressure-overload. To specifically address the effects of a diet rich in $\omega 3$-PUFAs from FO on NHE-1 in our study, we chose to use the $\omega 9$-MUFAs as a control fatty acids. These fatty are more abundantly present in the human diet and do not alter cardiac electrophysiology (den Ruijter et al., 2008). Therefore, rabbits were fed a diet rich in either $\omega 3$-PUFAs from FO or omega-9 monounsaturated fatty acids ( $\omega 9$-MUFAs) from high-oleic sunflower oil (HOSF) as control.

\section{MATERIALS AND METHODS ANIMALS AND DIET}

All experiments were carried out in accordance with guidelines of the local institutional animal care and use committee. In addition, the investigation conforms the Guide for the Care and Use of Laboratory Animals published by the US National Institutes of Health (NIH Publication No. 85-23, revised 1996).

Male New Zealand White rabbits (4 months old) received a diet ( 150 g/day; Research Diet Services, Wijk bij Duurstede, Netherlands) supplemented with either $1.25 \%$ (w/w) FO or $1.25 \%$ HOSF as control. Food consumption of every rabbit was measured and average food intake did not differ between FO and HOSF fed animals (data not shown). In the HF model, diet started 1 week before the surgical procedures to induce HF (see below). Lipids from the diet and the left ventricular tissue were extracted with the method of Folch et al. (1957). Table 1 summarizes the fatty acid composition of these diets. In short, the total PUFA content was higher in the $\omega 3$-PUFAs diet due to a larger amount of both EPA and DHA.

Heart failure was induced by combined volume- and pressureoverload in two sequential surgical procedures as described previously in detail (Vermeulen et al., 1994; Baartscheer et al., 2003a; Verkerk et al., 2007). In short, volume overload was produced by catheter-induced damage to the aortic valve until pulse pressure was increased by about $100 \%$. Three weeks later, pressureoverload was created by abdominal aortic stenosis by ligation of
Table 1 | Fatty acid composition of $\omega 9$-MUFA and $\omega 3$-PUFA diets.

\begin{tabular}{|c|c|c|}
\hline & $\omega 9-M U F A$ & $\omega 3$-PUFA \\
\hline \multicolumn{3}{|l|}{ SATURATED FATTY ACIDS } \\
\hline Total & 16.2 & 21.8 \\
\hline \multicolumn{3}{|c|}{ MONOUNSATURATED FATTY ACIDS } \\
\hline Total & 44.0 & 17.9 \\
\hline 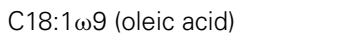 & 42.4 & 12.2 \\
\hline \multicolumn{3}{|c|}{ POLYUNSATURATED FATTY ACIDS } \\
\hline Total & 37.6 & 56.6 \\
\hline 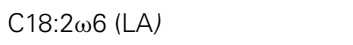 & 30.5 & 26.8 \\
\hline 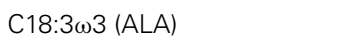 & 6.85 & 7.12 \\
\hline $\mathrm{C} 20: 4 \omega 6$ (AA) & 0.00 & 0.57 \\
\hline C20:5 $\omega 3$ (EPA) & 0.1 & 9.2 \\
\hline $\mathrm{C} 22: 6 \omega 3$ (DHA) & 0.1 & 6.3 \\
\hline Other, unidentified fatty acids & 2.2 & 3.6 \\
\hline
\end{tabular}

Fatty acid composition expressed as percentage of total fatty acids. W9-MUFA, high-oleic sunflower oil; $\omega 3$-PUFA, fish oil; LA, linoleic acid; $A L A$, $\alpha$-linolenic acid; $A A$, arachidonic acid; EPA, eicosapentaenoic acid; $D H A$, docosahexaenoic acid. The sum of listed components is less than the totals indicated here, since not all components were analyzed.

approximately 50\%. After 3 weeks for the healthy animals and after 4 months for the HF animals, the rabbits were anesthetized [(ketamine (50 mg i.m.) and xylazine (10 mg i.m.)], heparinized (5000 IU), and killed by intravenous injection of pentobarbital (240 mg).

\section{CELL PREPARATION}

Single midmyocardial myocytes were isolated by enzymatic dissociation from the most apical part of the left ventricular free wall as described previously (de Groot et al., 2003). Small aliquots of cell suspension were put in a recording chamber on the stage of an inverted microscope. Myocytes were allowed to adhere for 5 min after which superfusion with Tyrode's solution was started.

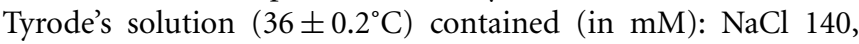
$\mathrm{KCl} 5.4, \mathrm{CaCl}_{2}$ 1.8, $\mathrm{MgCl}_{2}$ 1.0, glucose 5.5, HEPES 5.0, $\mathrm{pH} 7.4$ $(\mathrm{NaOH})$. Quiescent rod-shaped cross-striated myocytes with a smooth surface were selected for measurements.

\section{INTRACELLULAR pH MEASUREMENTS}

Intracellular $\mathrm{pH}\left(\mathrm{pH}_{\mathrm{i}}\right)$ was measured in carboxy-seminaphthorhodafluor-1 (SNARF-AM, Molecular Probes) loaded myocytes as described previously (Baartscheer et al., 2003a; van Borren et al., 2004). In short, myocytes were excited at $515 \mathrm{~nm}$ ( $75 \mathrm{~W}$ Xenon arc lamp) and dual wavelength emission of SNARF was recorded at wavelengths of $580 \mathrm{~nm}\left(I_{580}\right)$ and $640 \mathrm{~nm}\left(I_{640}\right)$. A rectangular adjustable slit ensured negligible background fluorescence levels. As shown in a typical example in Figure 1A, the $I_{580} / I_{640}$ ratio was calibrated by a series of precisely set $\mathrm{pH}$ solutions that contained $140 \mathrm{mM} \mathrm{K}^{+}$instead of $\mathrm{Na}^{+}$and the $\mathrm{K}^{+} / \mathrm{H}^{+}$ionophore nigericin (10 $\mu \mathrm{M}$; Sigma). Figure 1B shows the resulting calibration curve were the 580/640 ratios were plot against the $\mathrm{pH}_{\mathrm{i}}$.

\section{Intrinsic buffering power}

In general, activities of acid loaders or extruders are expressed as the amount of acid or base extruded or loaded per second, the 

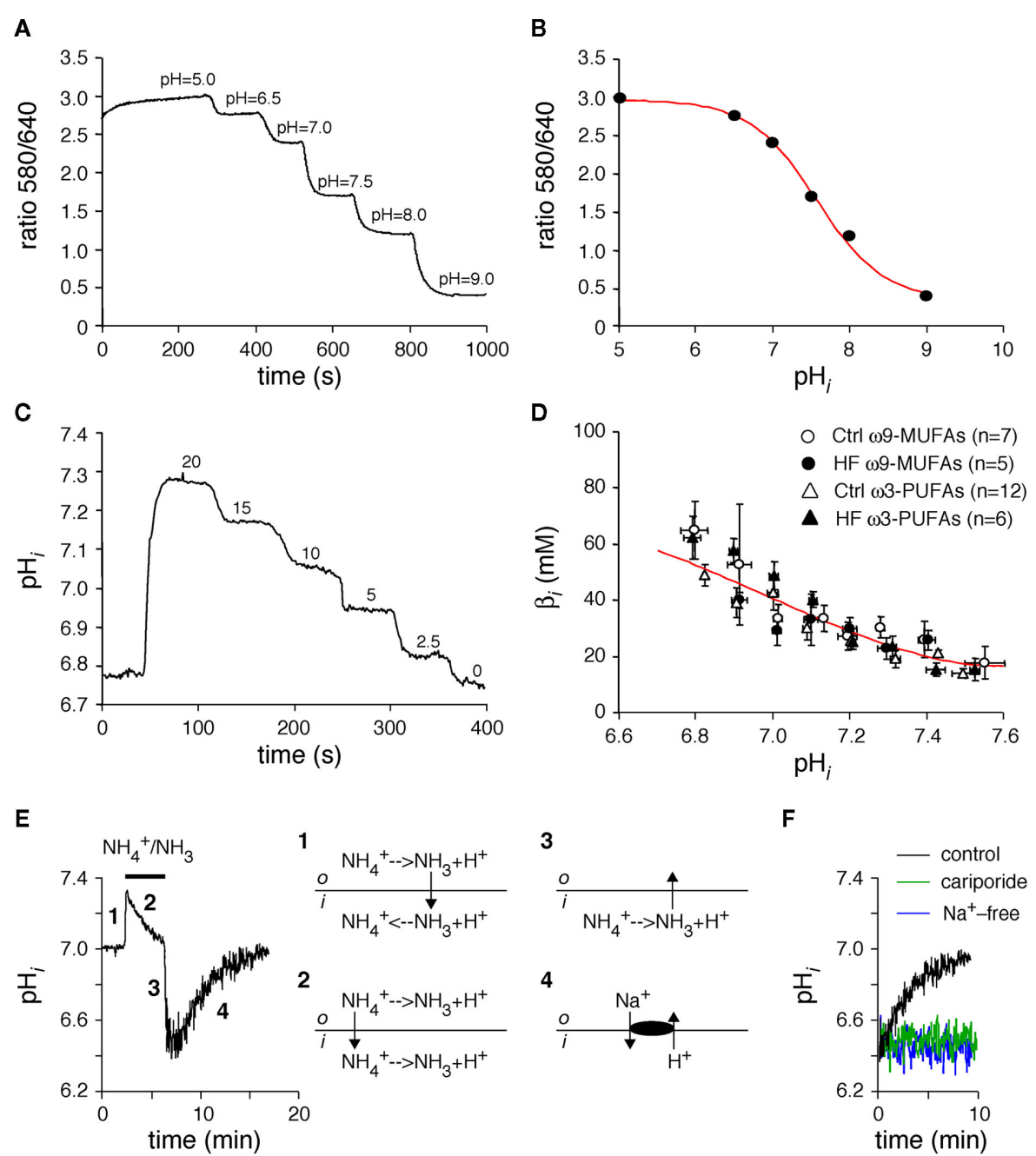

FIGURE 1 | (A,B) In vivo calibration curve of SNARF-AM. To determine calibration curve myocytes were loaded with SNARF-AM and superfused in presence op nigericin with several high $\mathrm{K}^{+}$solutions at various $\mathrm{pH}_{\circ}$ values (A). When the external and internal $\mathrm{K}^{+}$free concentrations are equal, $\mathrm{pH}_{\mathrm{i}}$ is the same as $\mathrm{pH}_{\mathrm{o}}$. The calibration curve (B) was obtained by plotting the ratios $(580 / 640)$ against the corresponding $\mathrm{pH}_{0}$. The red line represents a Henderson-Hasselbalch fit through these data, which revealed a maximum ratio of 2.97 and a minimum ratio of 0.36 and a $p K_{a}$

of 7.57. (C,D) Determination of the intrinsic sarcoplasmic buffer power $\left(\beta_{\mathrm{i}}\right)$. Typical example of the "stepwise reduction in extracellular $\mathrm{NH}_{3} / \mathrm{NH}_{4}{ }^{+}$ approach" in a myocyte isolated from a healthy, w3-PUFA fed animal (C), and $\mathrm{pH}_{i}-\beta^{i}$ relationships of $\omega 3$-PUFA and $\omega 9$-MUFA myocytes of both healthy rabbits (Ctrl) and the rabbits with heart failure (HF). (E) Typical example and schematic explanation of an ammonium prepulse. (F) Typical examples of effects of $\mathrm{Na}^{+}$-free conditions and cariporide on the acid load recovery in HEPES-buffered conditions.

proton flux $\left(J_{\mathrm{H}}\right.$; Roos and Boron, 1981). Changes in $\mathrm{pH}_{\mathrm{i}}$ are not linearly related to $J_{\mathrm{H}}$ due to the presence of a $\mathrm{pH}_{\mathrm{i}}$-dependent intrinsic sarcoplasmic buffer power $\left(\beta_{\mathrm{i}}\right)$. $\beta_{\mathrm{i}}$ was determined by the "stepwise reduction in extracellular $\mathrm{NH}_{3} / \mathrm{NH}_{4}{ }^{+}$approach" as described previously (Boyarsky et al., 1988), and shown in the typical example of Figure 1C. With each stepwise decrease in extracellular $\mathrm{NH}_{3} / \mathrm{NH}_{4}{ }^{+}$, the amount of protons delivered to the cytoplasm $(\Delta[\mathrm{acid}] \mathrm{i})$ was considered equal to the resultant change in intracellular $\mathrm{NH}_{4}{ }^{+}$concentration, which can be calculated from the observed $\mathrm{pH}_{\mathrm{i}} . \Delta \mathrm{pH}_{\mathrm{i}}$ was taken as the change in $\mathrm{pH}_{\mathrm{i}}$ produced by the stepwise decrease in extracellular $\mathrm{NH}_{3} / \mathrm{NH}_{4}{ }^{+} . \beta_{\mathrm{i}}$ was then calculated as $-\Delta[\operatorname{acid}]_{\mathrm{i}} / \Delta \mathrm{pH}_{\mathrm{i}}$ (Roos and Boron, 1981). $\beta_{\mathrm{i}}$ was assigned to the mean of the two $\mathrm{pH}_{\mathrm{i}}$ values used for its calculation. Figure 1D shows the $\mathrm{pH}_{\mathrm{i}}-\beta_{\mathrm{i}}$ relationships of myocytes isolated from $\omega 3$-PUFA and $\omega 9$-MUFA fed healthy rabbits and of myocytes of $\omega 3$-PUFA and $\omega 9$-MUFA fed rabbits with model of volume- and pressure-overload. The $\mathrm{pH}_{\mathrm{i}}-\beta_{\mathrm{i}}$ relationships did not differ significantly, indicating that neither the diets nor HF affect the $\beta_{\mathrm{i}}$.

\section{NHE-1 activity}

$\mathrm{Na}^{+} / \mathrm{H}^{+}$-exchanger isoform- 1 activity was measured in HEPESbuffered conditions as recovery rate from acidosis due to ammonium prepulses as described previously (van Borren et al., 2004). Figure 1E shows a typical example and explanation of the $\mathrm{pH}$ changes in response to an ammonium prepulse. In short, $20 \mathrm{mM}$ $\mathrm{NH}_{4} \mathrm{Cl}\left(\mathrm{NH}_{4}{ }^{+} / \mathrm{NH}_{3}\right)$ was rapidly added to the Tyrode's solution resulting instantly in alkalinization of myocytes (Figure 1E, phase 
1), after which they slowly recovered from alkalization mainly because of $\mathrm{NH}_{4}{ }^{+}$influx (Figure 1E, phase 2). After withdrawal of $\mathrm{NH}_{4}{ }^{+} / \mathrm{NH}_{3}$ from the extracellular solutions all intracellular $\mathrm{NH}_{4}{ }^{+}$ is converted to $\mathrm{NH}_{3}$ which leaves the myocyte and the remaining $\mathrm{H}^{+}$acidifies the sarcoplasm (Figure 1E, phase 3). Subsequently, in HEPES-buffered solutions, the myocytes slowly recovered from the acid load due to NHE-1 activity (Figure 1E, phase 4). The recovery from acid load is $\mathrm{Na}^{+}$-dependent as well as blocked by cariporide (10 $\mu \mathrm{M}$; Figure $1 \mathbf{F})$, typical hallmarks of the NHE-1. From the $\mathrm{pH}_{\mathrm{i}}$ traces we computed the $\mathrm{dpH}_{\mathrm{i}} / \mathrm{dt}$ 's and multiplied these with $\beta_{\mathrm{i}}$ to arrive at $J_{\mathrm{NHE}-1}$.

\section{CELLULAR ELECTROPHYSIOLOGY}

Action potentials (APs) and delayed afterdepolarizations (DADs) were recorded with the perforated patch-clamp technique using an Axopatch 200B amplifier (Molecular Devices, Sunnyvale, CA, USA). Signals were low-pass filtered with a cut-off frequency of $2 \mathrm{kHz}$ and digitized at $3 \mathrm{kHz}$. Data acquisition and analysis were accomplished using custom software and potentials were corrected for liquid junction potential (Barry and Lynch, 1991). APs were elicited at $3 \mathrm{~Hz}$ by 3 -ms long, $1.2 \times$ threshold current pulses through the patch pipette. We analyzed resting membrane potential (RMP), maximal upstroke velocity $\left(V_{\max }\right)$, AP amplitude (APA), and AP duration at 20,50, and 90\% repolarization $\left(\mathrm{APD}_{20}, \mathrm{APD}_{50}\right.$, and $\mathrm{APD}_{90}$, respectively). Susceptibility to DADs were evoked by a $3-\mathrm{Hz}(10-\mathrm{s})$ rapid pacing episode followed by an 8-s pause (tracing period) in the presence of norepinephrine (100 nM, Centrafarm, Etten-Leur, The Netherlands). A DAD was defined as a temporary, short-lived deviation from (an otherwise stable) RMP of more than $2 \mathrm{mV}$. Data from five APs and five rapid pacing episode were averaged. Cell membrane capacitance, an electrophysiological measure of cell size, was estimated as we described previously in detail (Verkerk et al., 2004).

\section{STATISTICS}

Data are mean \pm SEM. Groups were compared using Two-Way Repeated Measures ANOVA followed by pairwise comparison using the Student-Newman-Keuls test, Fisher's exact test, or unpaired $t$-test. $P<0.05$ is considered statistical significant.

\section{RESULTS}

\section{$\omega 3$-PUFA RICH DIET RESULTS IN $\omega 3$-PUFAs INCORPORATED IN THE CELL MEMBRANE}

The diet rich in $\omega 3$-PUFAs from FO resulted in a significant increase of $\omega 3$-PUFAs EPA and DHA of the total amount of fatty acids extracted from the heart of both healthy and HF rabbits (Table 2). The total amount of monounsaturated fatty acids, however, was significantly lower in the $\omega 3$-PUFAs fed rabbit hearts compared to the $\omega 9$-MUFAs fed rabbit hearts. Thus, $\omega 3$-PUFAs from the diet were incorporated in the cell membrane at the expense of monounsaturated fatty acids.

\section{DIETARY $\omega 3$-PUFAs DO NOT AFFECT NHE-1 ACTIVITY IN HEALTHY RABBITS}

In a first series of experiments, we measured the NHE-1 in myocytes isolated from healthy rabbits. Body weight after 3 weeks of diet was similar in $\omega 3$-PUFA and $\omega 9$-MUFA fed animals $(3.1 \pm 0.2, n=9)$ vs. $2.9 \pm 0.2 \mathrm{~kg}(n=7), P>0.05)$. Figure $2 \mathrm{~A}$, top panel, shows representative recordings of the $\mathrm{pH}_{\mathrm{i}}$ recovery after an ammonium prepulse (see Materials and Methods) in a myocyte isolated from an $\omega 3$-PUFA and $\omega 9$-MUFA fed rabbit. The $\mathrm{pH}_{\mathrm{i}}$ recovery, and consequently the calculated $J_{\mathrm{NHE}-1}$ (Figure $2 \mathrm{~A}$, bottom panel), was virtually overlapping in the myocytes of $\omega 3$ PUFA and $\omega 9$-MUFA fed animals. Figure $2 \mathbf{B}$ shows the average $J_{\text {NHE- } 1}$ in the myocytes of $\omega 3$-PUFA $\omega 9$-MUFA fed animals. The average $J_{\text {NHE-1 }}$ was not significantly different in the myocytes of $\omega 3$-PUFA and $\omega 9$-MUFA fed animals at any of the $\mathrm{pH}_{\mathrm{i}}$ 's.

Table 2 | Phospholipid composition of the heart (\% of total fat extracted).

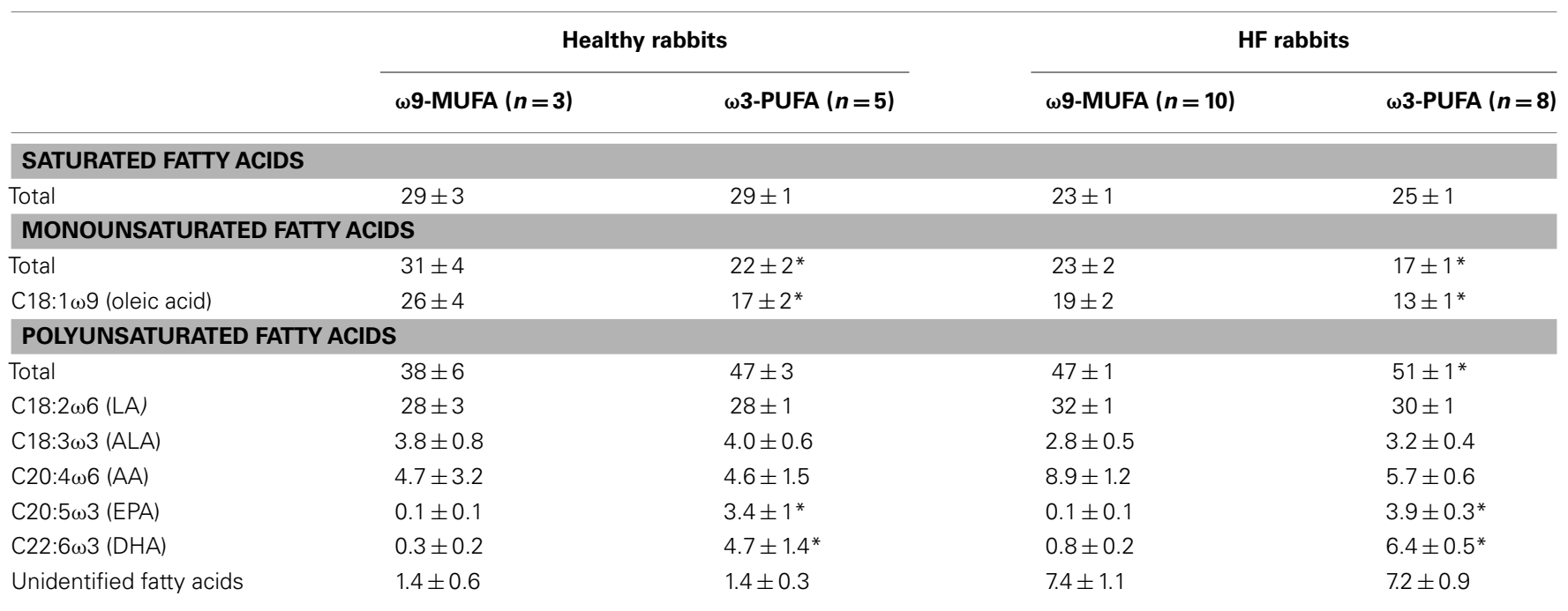

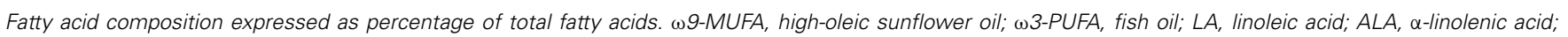

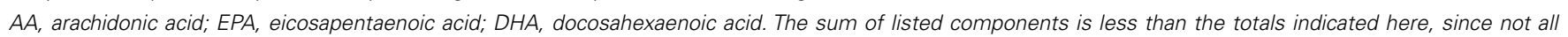
components were analyzed. ${ }^{*} P<0.05 \omega 9$ 9-MUFA vs. 3-PUFA diet. 

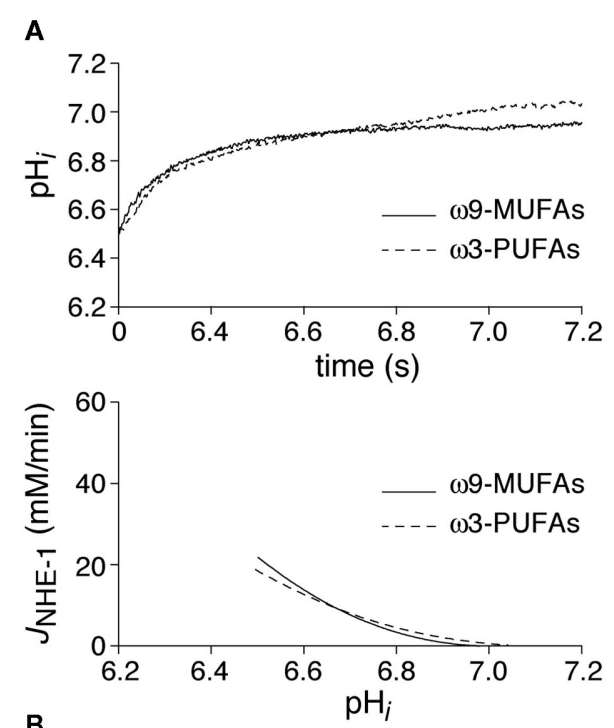

B

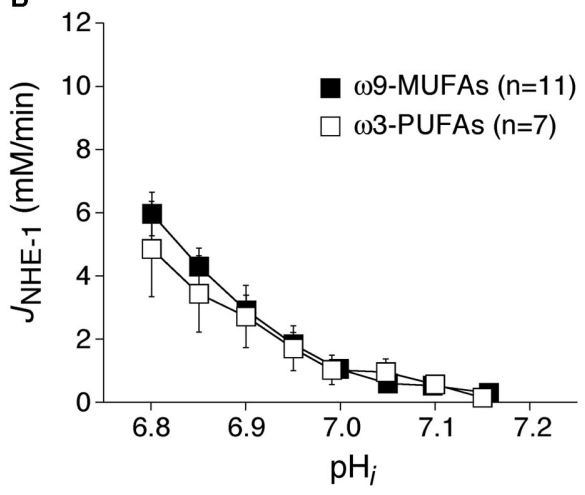

FIGURE 2 | (A) Typical examples of $\mathrm{pH}_{\mathrm{i}}$ recovery after an ammonium prepulse (top) and the calculated $J_{\text {NHE-1 }}$ (bottom) in an $\omega 9$-MUFA and w3-PUFA myocyte isolated from healthy animals. (B) Average $J_{\text {NHE-1 }}$ in myocytes of $\omega 9$-MUFA and $\omega 3$-PUFA fed healthy animals.

\section{DIETARY $\omega 3$-PUFAs REDUCES THE NHE-1 ACTIVITY IN A RABBIT MODEL OF VOLUME- AND PRESSURE-OVERLOAD}

In a second series of experiments, we studied the NHE-1 activity in myocytes isolated from rabbits that underwent model of volumeand pressure-overload for 4 months. Figure 3A, top panel, shows representative of the $\mathrm{pH}_{\mathrm{i}}$ recovery after an ammonium prepulse in a myocyte of an $\omega 3$-PUFA and $\omega 9$-MUFA fed animal. In the $\mathrm{HF}$ rabbits, $\mathrm{pH}_{\mathrm{i}}$ recovery after an ammonium prepulse was slower in the myocyte of the 13 -PUFA animal compared to that in the myocyte of the $\omega 9$-MUFA fed animal. Consequently, the calculated $J_{\text {NHE-1 }}$ was lower in the myocyte of the $\omega 3$-PUFA rabbit (Figure 3A, bottom panel). Figure 3B shows the average $J_{\mathrm{NHE}-1}$ in myocytes of $\omega 3$-PUFA and $\omega 9$-MUFA fed HF animals. The average $J_{\text {NHE-1 }}$ was significantly lower in myocytes of $\omega 3$-PUFA animals at $\mathrm{pH}$ values lower than $7.1(P<0.05)$.

\section{DIETARY $\omega 3$-PUFAs OPPOSE THE INCREASE IN NHE-1 ACTIVITY INDUCED BY HEART FAILURE}

In HF animals, but not in healthy animals, NHE-1 activity in $\omega 3$-PUFAs myocytes was significantly lower than in $\omega 9$-MUFAs
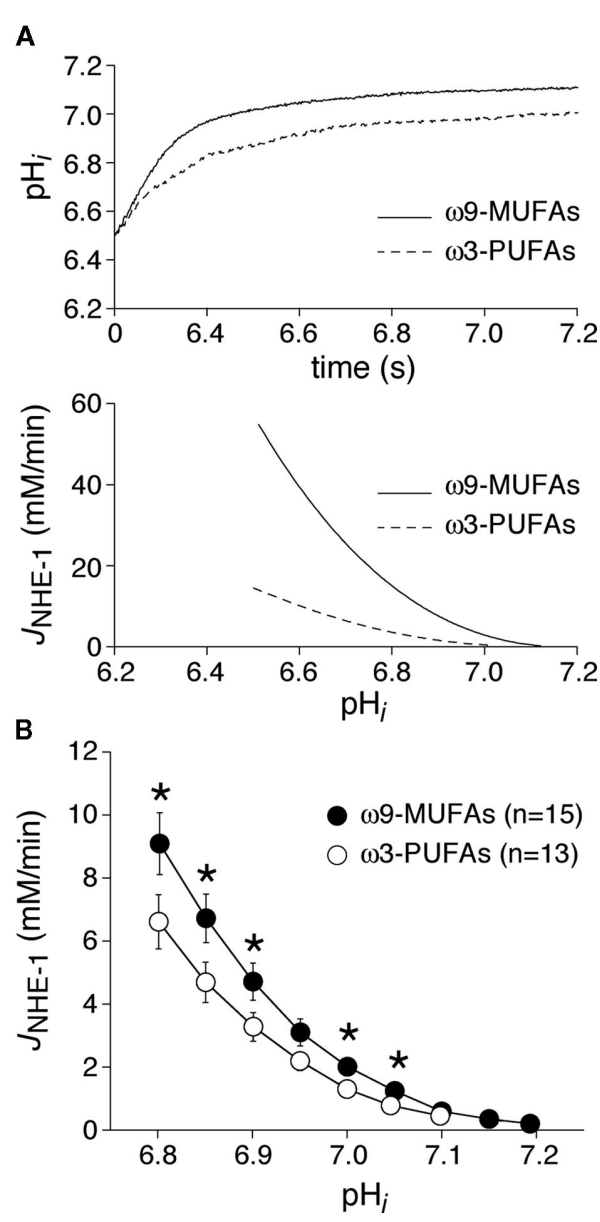

FIGURE 3 | (A) Typical examples of $\mathrm{pH}_{\mathrm{i}}$ recovery after an ammonium prepulse (top) and the calculated $J_{\mathrm{NHE}-1}$ (bottom) in an $\omega 9$-MUFA and $\omega 3$-PUFA myocyte isolated from rabbit which underwent volume- and pressure-overload. (B) Average $J_{\text {NHE-1 }}$ in myocytes isolated from $\omega 9$-MUFA and $\omega 3$-PUFA fed rabbits with volume- and pressure-overload. ${ }^{*} P<0.05$.

myocytes (Figures 2B and 3B). Previous studies demonstrate that the NHE-1 activity is significantly increased in animal and patients with HF (Baartscheer et al., 2003a; Chahine et al., 2005; van Borren et al., 2006). This suggests that dietary $\omega 3$-PUFAs suppress the increase in NHE-1 activity in our rabbit HF model. Figure 4 shows the averages $J_{\mathrm{NHE}-1}$ at $\mathrm{pH} 7.0$ of myocytes of $\omega 3$-PUFA and $\omega 9$-MUFA fed healthy and HF animals. HF significantly increased the $J_{\text {NHE- } 1}$ in myocytes of $\omega 9$-MUFA fed animals $(P<0.05)$, but not in myocytes of $\omega 3$-PUFA fed animals. Thus, a diet rich in $\omega 3$-PUFAs suppresses the increase in NHE-1 activity associated with HF.

\section{DIETARY $\omega 3$-PUFAs REDUCES THE INCIDENCE OF DADs IN A RABBIT MODEL OF VOLUME- AND PRESSURE-OVERLOAD}

Volume- and pressure-overload in rabbit increased the NHE-1 activity resulting in elevated $\left[\mathrm{Na}^{+}\right]_{\mathrm{i}}$ and secondarily to increased $\left[\mathrm{Ca}^{2+}\right]_{\mathrm{i}}$ (Baartscheer et al., 2003a). The altered $\mathrm{Ca}^{2+}$ handling in $\mathrm{HF}$ is associated with spontaneous $\mathrm{Ca}^{2+}$ release from the sarcoplasmic reticulum (SR; Baartscheer et al., 2003b), which activate 


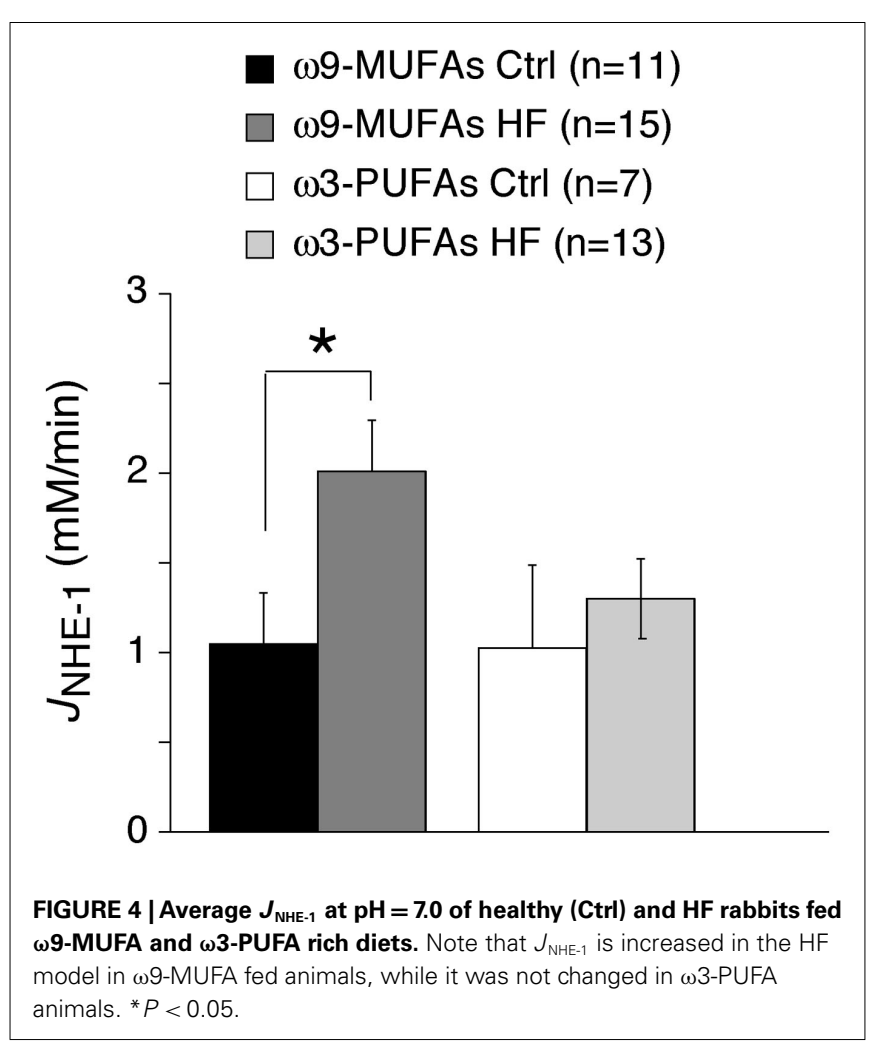

the transient inward current, Iti, resulting in DADs (Verkerk et al., 2000a). 63 -PUFAs, and not $\omega 9$-MUFA, suppress the increase in NHE-1 activity in our rabbit model of volume- and pressureoverload. Thus, we hypothesized that the incidence of DADs is lower in myocytes of $\omega 3$-PUFAs fed HF rabbits compared to those of $\omega 9$-MUFA fed HF rabbits. Next, we tested the susceptibility to induced DADs in HF myocytes by rapid pacing in the presence of $100 \mathrm{nM}$ noradrenalin.

Figure 5A shows typical examples of APs and DAD of myocytes isolated from an $\omega 3$-PUFA and an $\omega 9$-MUFA fed HF animal. In the myocyte of the $\omega 9$-MUFA fed HF rabbit, but not in the myocyte of the $\omega 3$-PUFA fed HF rabbit, a DAD (arrow) was present. The amount of myocytes with more than one DAD was significantly lower $(P<0.05$, Fisher's exact test) in $\omega 3$-PUFA fed HF rabbits compared to those of $\omega 9$-MUFA fed HF animal (Table 3 ). In addition, the number of DADs was significantly lower in the myocytes of $\omega 3$-PUFA fed HF rabbits (Figure 5B). Figure 5C summarizes the average $\mathrm{AP}$ characteristics at $3 \mathrm{~Hz}$ of myocytes isolated from $\omega 3$-PUFA and an $\omega 9$-MUFA fed HF animal in the presence of $100 \mathrm{nM}$ noradrenaline. In presences of $100 \mathrm{nM}$ noradrenaline, no AP differences were observed between myocytes of $\omega 3$-PUFA and an $\omega 9$-MUFA fed HF animal.

HYPERTROPHY IS SIMILAR IN $\omega 3$-PUFAs AND $\omega 9$-MUFAs FED RABBITS Various studies demonstrate that $\omega 3$-PUFAs suppress development of hypertrophy and HF (Takahashi et al., 2005; Duda et al.,

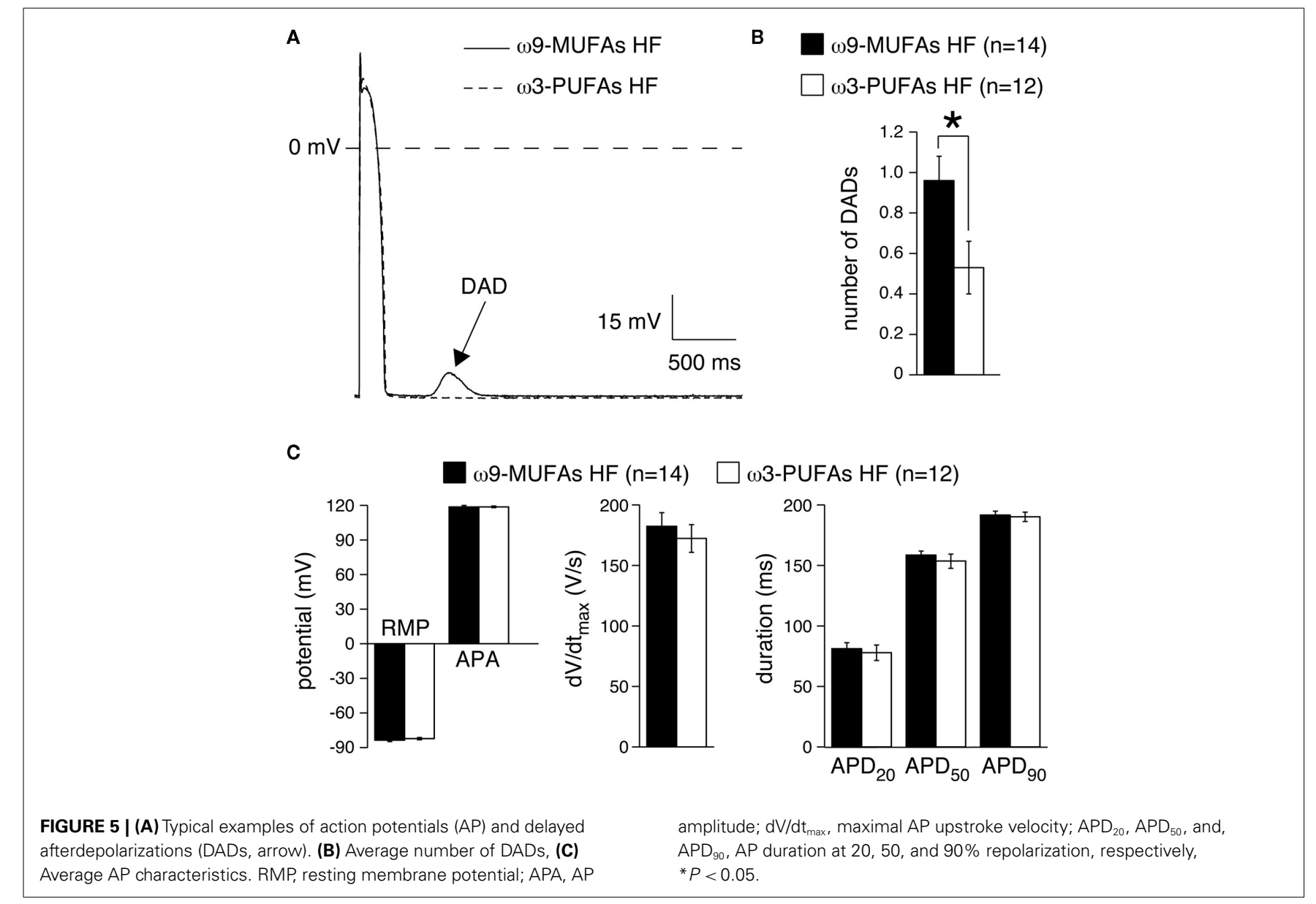


2007; Ramadeen et al., 2010; Chen et al., 2011). Because cardiac hypertrophy leads to a decrease of the surface to volume ratio of myocytes, an increased number of NHE-1 proteins are required to maintain a normal "cytoplasmic" NHE-1 mediated acid load recovery. The maintained cytoplasmic NHE-1 activity observed in cardiomyocytes from w3-PUFAs treated HF rabbits (Figure 4) may thus be explained also by a lower degree of hypertrophy. Therefore, we finally analyzed important parameters for hypertrophy and HF in $\omega 3$-PUFA and $\omega 9$-MUFA fed rabbits, which underwent volume- and pressure-overload. Body, lung, and heart weight were similar in $\omega 3$-PUFA and $\omega 9$-MUFA rabbits (Figure 6A). Consequently, relative lung weight and relative heart weight, an index of cardiac hypertrophy, were not significantly different (Figure 6B). While previously we observed relative heart weights of $2.2-2.5$ in non-failing rabbits with a standard chow diet (Baartscheer et al., 2003a,b, 2005, 2008; de Groot et al., 2003; van Borren et al., 2006), the relative heart weights in the present study of $\omega 3$-PUFA and $\omega 9$-MUFA fed rabbits were $3.6 \pm 0.26$ and $3.3 \pm 1.13$, respectively. Thus, despite the absence of differences in degree of hypertrophy, both $\omega 3$-PUFA and $\omega 9$-MUFA fed HF rabbit hearts are equally hypertrophied. Moreover, cell capacitance, an electrophysiological measure of cell size, was not significantly different between myocytes of $\omega 3$ PUFA and $\omega 9$-MUFA rabbits (Figure 6C). Furthermore, the presence of ascites assessed at autopsy was the same in $\omega 3$-PUFA

Table 3 | Susceptibility to induce delayed afterdepolarizations (DADs).

\begin{tabular}{lll}
\hline & Fewer than 1 DAD & 1 or more DAD \\
\hline w9-MUFA & 2 & 12 \\
$\omega 3-P U F A$ & 7 & 5
\end{tabular}

Number of myocytes. Values indicate the number of myocytes having $<1$ or $\geq 1$ $D A D$ (average of five tracings). The susceptibility to induce DADs is significantly lower in $\omega 3$-PUFA compared to $\omega 9$-MUFA myocytes $(P<0.05$, Fisher's exact test). and $\omega 9$-MUFA rabbits. These data indicate that the degree of hypertrophy and HF are similar in $\omega 3$-PUFA and $\omega 9$-MUFA fed rabbits.

\section{DISCUSSION}

\section{OVERVIEW}

In this study we examined the effects of dietary $\omega 3$-PUFAs on NHE-1 of myocytes from healthy and failing hearts. In general, NHE-1 inhibition is thought to be a pharmacological tool for the treatment of various detrimental cardiac conditions such as ischemia/reperfusion injury, arrhythmias, hypertrophy, and HF. In many pre-clinical studies, NHE-1 inhibition has been shown to reduce ischemia/reperfusion injury (Lee et al., 2005; Ayoub et al., 2010). In clinical trials, however, the cardioprotective effects of NHE-1 inhibition were less clear and the treatment with the NHE1 inhibitor cariporide was associated with significantly greater incidence of stroke (Fliegel and Karmazyn, 2004). These adverse effects halted the further use of cariporide as cardioprotective agent.

Cardiac NHE-1 activity is also significantly increased in animal and patients with HF (Baartscheer et al., 2003a; Chahine et al., 2005). Pre-clinical studies demonstrated that chronic inhibition of NHE-1 leads to reversal of cardiac fibrosis, hypertrophy and $\mathrm{HF}$, and improved contractility in HF models in mice (Engelhardt et al., 2002), rats (Camillión de Hurtado et al., 2002; Chen et al., 2004), and rabbit (Baartscheer et al., 2005, 2008). In rabbit studies, a diet containing the NHE-1 inhibitor cariporide not only reversed hypertrophy and reduced signs of HF, but also reversed cardiac ionic and electrical remodeling and prevented changes in myocyte dimensions, AP duration, and NHE-1 fluxes (Baartscheer et al., 2005, 2008). In addition, $\mathrm{Ca}^{2+}$ homeostasis remained undisturbed, and no increase of the incidence of $\mathrm{Ca}^{2+}$ after transient dependent DADs occurred (Baartscheer et al., 2005). From the prevention of excessive fibrosis, prolongation of AP duration, and DADs (Nuss et al., 1999; Marx et al., 2000; Sipido et al., 2000; Janse, 2004; Pogwizd and Bers, 2004), one may infer that NHE-1 inhibition is
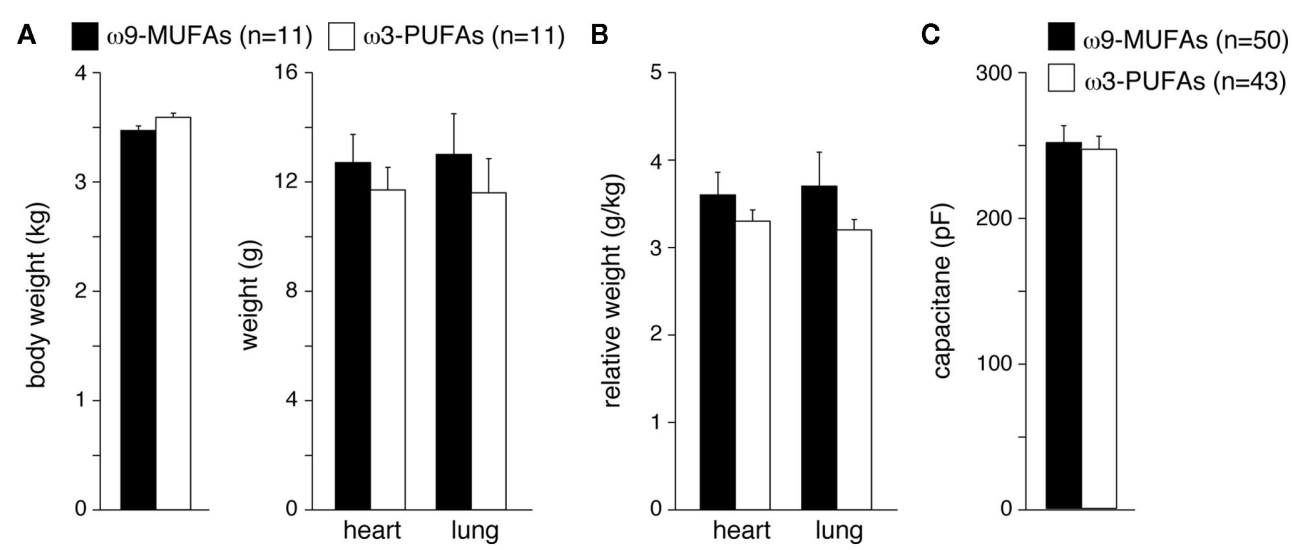

FIGURE 6 | (A) Average body, lung, and heart weight in $\omega 3$-PUFA and $\omega 9$-MUFA fed rabbits which underwent volume- and pressure-overload. $n$, Number of rabbits (B), Relative lung weight and relative heart weight, an index of cardiac hypertrophy, in

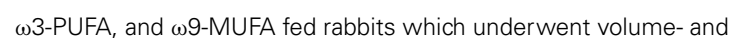
pressure-overload. (C) Average cell membrane capacitance of myocytes isolated from $\omega 3$-PUFA and $\omega 9$-MUFA rabbits. $n$, Number of myocytes. ${ }^{*} P<0.05$. 
also anti-arrhythmic. Thus, at least part of the beneficial effects of $\omega 3$-PUFAs may be attributed to NHE-1 inhibition during HF.

\section{DIETARY $\omega 3$-PUFAs DO NOT SUPPRESS THE NHE-1 IN MYOCYTES OF HEALTHY ANIMALS}

In myocytes isolated from healthy animals, we found that $\omega 3$ PUFAs do not affect the NHE-1 activity as compared to $\omega 9$ MUFAs (Figure 2). Our results contrast with a study by Goel et al. (2002) that showed that $\omega 3$-PUFAs reduced the NHE-1 activity. This discrepancy is likely due to study design. We studied dietary $\omega 3$-PUFAs intake that causes $\omega 3$-PUFA incorporation into cardiac cell membranes (Owen et al., 2004), whereas Goel et al. (2002) studied direct application of $\omega 3$-PUFAs on cardiac myocytes. Acutely applied $\omega 3$-PUFAs and incorporated $\omega 3$-PUFAs have different effects on cardiac electrophysiology (den Ruijter et al., 2007, 2010; Verkerk et al., 2009), and our study suggests that it also has a different effect on $\mathrm{pH}_{\mathrm{i}}$. Dietary $\omega 3$-PUFAs intake does not affect the resting $\mathrm{pH}_{\mathrm{i}}$ in healthy animals (present study), while acute administration resulted in acidosis (Aires et al., 2003), which could well explain the lower apparent NHE-1 activity observed by Goel et al. Other explanations may be the differences in species (pig vs. rabbit) and the technique used to measure NHE-1 activity (radioactive $\mathrm{Na}^{+}$uptake in cell suspensions vs. single cell fluorescence).

\section{DIETARY $\omega 3$-PUFAs SUPPRESS NHE-1 UPREGULATION IN A RABBIT MODEL OF VOLUME- AND PRESSURE-OVERLOAD}

In our rabbit model of volume- and pressure-overload, we found that the NHE-1 activity in $\omega 3$-PUFAs myocytes was significantly lower than in 69 -MUFAs myocytes (Figure 3). The mechanisms for the lower NHE-1 activity are unknown. One may speculate that $\omega 3$-PUFAs affect membrane fluidity (Jahangiri et al., 2000), resulting in a decrease of NHE-1 activity (Bookstein et al., 1997). This membrane fluidity theory is frequently used to explain the effects of $\omega 3$-PUFAs on membrane channels, however, but the lack of significant effects of $\omega 3$-PUFAs on NHE-1 in healthy animals is not in line of this hypothesis.

A second hypothesis is that $\omega 3$-PUFAs attenuate cardiac hypertrophy (Takahashi et al., 2005; Duda et al., 2007; Ramadeen et al., 2010; Chen et al., 2011), resulting in a decrease of NHE-1 activity (Baartscheer et al., 2005). In the present study, however, the relative heart weight and cell capacitance, both indices of cardiac hypertrophy, did not differ between $\omega 3$-PUFAs and $\omega 9$-MUFAs fed rabbits or their myocytes, respectively (Figure 6). This excludes differences in hypertrophy as a likely mechanism. The unaltered degree of hypertrophy is in contrast with observations in mice with transverse aortic constriction (Chen et al., 2011) and juvenile visceral steatosis (Takahashi et al., 2005), rats with abdominal aortic banding (Duda et al., 2007), and rapid-paced dogs (Ramadeen et al., 2010) where dietary supplementation of $\omega 3$-PUFAs attenuated cardiac hypertrophy. This discrepancy may be explained by differences in HF model, species, $\omega 3$-PUFAs concentration, but also to the control diets used. In our study, the control ( $\omega 9$-MUFAs) diet was supplemented with HOSF, while in the other studies the control diet was standard chow or supplemented with corn oil. The importance of a proper control diet is supported by the finding that the relative heart weight of $\omega 9$-MUFAs fed HF rabbits was $\approx 3.6$ (Figure 6), while in the same rabbit HF model with a standard chow diet we previously measured relative heart weights of 4.4-6.0 in our laboratory (Baartscheer et al., 2003a,b, 2005, 2008; de Groot et al., 2003; van Borren et al., 2006; den Ruijter et al., 2008). This suggests that both $\omega 3$-PUFAs and $\omega 9$-MUFAs diets reduce the degree of hypertrophy. Further studies are required to address this.

A third hypothesis is that dietary $\omega 3$-PUFAs affect cell signaling and enzymes important for NHE-1 activity. The NHE is not only activated by $\mathrm{pH}_{\mathrm{i}}$ but also by a number of other stimuli. NHE-1 activity is accelerated in response of endothelin, angiotensin II, and $\mathrm{G}$ protein and second messenger stimulation of PKC (diacylglycerol) and PKA (forskolin, $\beta 1$-adrenoreceptor agonists; Kandasamy et al., 1995; Karmazyn et al., 2001; Díaz et al., 2010). Also, mitogenactivated protein (MAP) kinase-dependent pathways result in the phosphorylation of the NHE (Sartori et al., 1999). W3-PUFAs affect several of these NHE-1 stimuli. They reduce diacylglycerol and $\mathrm{PKC}$, activate the parasympathetic nervous system, and reduce angiotensin-converting enzyme (ACE) activity (Mohan and Das, 2001; Seung-Kim et al., 2001; Takahashi et al., 2005), although the latter is not a consistent finding (Ogawa et al., 2009). An intriguing question is why the NHE-1 activity in myocytes of $\omega 3$-PUFA fed animals is lower than in myocytes of $\omega 9$-MUFA fed animals in our model of volume- and pressure-overload, while it is not different in healthy rabbits. This suggests that the NHE-1 reduction is due to changes in cell signaling pathways active during HF (Onohara et al., 2006; Niizeki et al., 2008). One can speculate that the lower NHE-1 activity also reduces the degree of hypertrophy and $\mathrm{HF}$, but this was not observed in the present study, suggesting that NHE-1 is more sensitive for $\omega 3$-PUFAs modulation of cellular signaling pathways than hypertrophy and HF. Alternatively, the time required for hypertrophy and $\mathrm{HF}$ attenuation might be longer than that for NHE-1 reduction. The decreased NHE-1 activity may also be the result of a decreased expression of NHE-1.

\section{DIETARY $\omega 3$-PUFAs SUPPRESS DADs}

In our HF model of volume-and pressure-overload, we observed that the susceptibility for DAD development was significantly lower in myocytes of $\omega 3$-PUFAs fed rabbits compared to those of $\omega 9$-MUFAs fed rabbits (Table 3; Figure 6B). DADs occur in $\left[\mathrm{Ca}^{2+}\right]_{\mathrm{i}}$ overload condition (Verkerk et al., 2000a, and primary references cited therein). Thus, our results indicate that myocytes of $\omega 3$-PUFAs fed failing rabbits are less sensitive for $\left[\mathrm{Ca}^{2+}\right]_{i}$ overload development than those of $\omega$ 9-MUFAs fed failing rabbits. According to the importance of the NHE-1 for $\left[\mathrm{Ca}^{2+}\right]_{\mathrm{i}}$ (Baartscheer et al., 2003a), it is tempting to speculate that this is due to the lower NHE1 activity in myocytes of $\omega 3$-PUFAs fed HF rabbits. Previously we observed multiple changes in ionic currents due to dietary and acute $\omega 3$-PUFAs resulting in AP shortening (Verkerk et al., 2006) and reduced susceptibility of early afterdepolarizations and DADs development (den Ruijter et al., 2006, 2008; Berecki et al., 2007).

Dietary $\omega 3$-PUFAs caused an increase of $I_{\mathrm{K} 1}$ resulting in a more stable RMP (Verkerk et al., 2006). The latter will result in smaller DAD amplitudes. In addition, dietary w3-PUFAs decreased $I_{\text {NCX }}$ (Verkerk et al., 2006), which carries the transient inward current, $I_{\mathrm{ti}}$, responsible for DADs (Verkerk et al., $2000 \mathrm{a}$, and primary references cited therein). Decreased $I_{\mathrm{NCX}}$ 
may therefore also result in DADs of smaller amplitude. However, while both changes may reduce the DAD amplitude, they will not reduce the propensity to spontaneous $\mathrm{Ca}^{2+}$ release of the SR and thus DADs. Previously, we observed AP shortening due to dietary $\omega 3$-PUFAs (Verkerk et al., 2006). AP shortening leads to an increased diastolic interval, favoring removal of excess $\mathrm{Ca}^{2+}$ from the cytosol. This will reduce $\left[\mathrm{Ca}^{2+}\right]_{\mathrm{i}}$ overload conditions and DAD occurrence (Verkerk et al., 2000b, and primary refs. cited therein). However, in presence of $100 \mathrm{nM}$ noradrenaline, AP duration did not differed significantly between myocytes of $\omega 3$-PUFAs and $\omega 9$-MUFAs fed HF rabbits (Figure 5C). Thus, in the present study the role of AP duration in susceptibility of DADs is limited, although this cannot be entirely excluded in the absence of data on intracellular calcium and sodium activity.

\section{REFERENCES}

Aires, V., Hichami, A., Moutairou, K., and Khan, N. A. (2003). Docosahexaenoic acid and other fatty acids induce a decrease in $\mathrm{pH}_{\mathrm{i}}$ in Jurkat T-cells. Br. J. Pharmacol. 140, 1217-1226.

Ayoub, I. M., Kolarova, J., and Gazmuri, R. J. (2010). Cariporide given during resuscitation promotes return of electrically stable and mechanically competent cardiac activity. Resuscitation 81, 106-110.

Ayoub, I. M., Kolarova, J., Yi, Z., Trevedi, A., Deshmukh, H., Lubell, D. L., Franz, M. R., Maldonado, F. A., and Gazmuri, R. J. (2003). Sodiumhydrogen exchange inhibition during ventricular fibrillation: beneficial effects on ischemic contracture, action potential duration, reperfusion arrhythmias, myocardial function, and resuscitability. Circulation 107, 1804-1809.

Baartscheer, A., Hardziyenka, M., Schumacher, C. A., Belterman, C. N. W., van Borren, M. M. G. J., Verkerk, A. O., Coronel, R., and Fiolet, J. W. T. (2008). Chronic inhibition of the $\mathrm{Na}^{+} / \mathrm{H}^{+}$- exchanger causes regression of hypertrophy, heart failure, and ionic and electrophysiological remodelling. Br. J. Pharmacol. 154, 1266-1275.

Baartscheer, A., Schumacher, C. A., van Borren, M. M. G. J., Belterman, C. N. W., Coronel, R., and Fiolet, J. W. T. (2003a). Increased $\mathrm{Na}^{+} / \mathrm{H}^{+}$exchange activity is the cause of increased $\left[\mathrm{Na}^{+}\right]_{\mathrm{i}}$ and underlies disturbed calcium handling in the rabbit pressure and volume overload heart failure model. Cardiovasc. Res. 57, 1015-1024.

Baartscheer, A., Schumacher, C. A., Belterman, C. N. W., Coronel, R., and Fiolet, J. W. T. (2003b). SR calcium handling and calcium aftertransients in a rabbit model of heart failure. Cardiovasc. Res. 58, 99-108.

Baartscheer, A., Schumacher, C. A., van Borren, M. M. G. J., Belterman, C. N. W., Coronel, R., Opthof, T., and Fiolet, J. W. T. (2005). Chronic inhibition of $\mathrm{Na}^{+} / \mathrm{H}^{+}$-exchanger attenuates cardiac hypertrophy and prevents cellular remodeling in heart failure. Cardiovasc. Res. 65, 83-92.

Baartscheer, A., and van Borren, M. M. G. J. (2008). Sodium ion transporters as new therapeutic targets in heart failure. Cardiovasc. Hematol. Agents Med. Chem. 6, 229-236.

Bak, M. I., and Ingwall, J. S. (2003). Contribution of $\mathrm{Na}^{+} / \mathrm{H}^{+}$exchange to $\mathrm{Na}^{+}$overload in the ischemic hypertrophied hyperthyroid rat heart. Cardiovasc. Res. 57, 1004-1014.

Barry, P. H., and Lynch, J. W. (1991). Liquid junction potentials and small cell effects in patch clamp analysis. $J$. Membr. Biol. 121, 101-107.

Berecki, G., den Ruijter, H. M., VerkBaartscheer, A., Bakker, D., Boukens, B. J., van Ginneken, A. C. G., Fiolet, J. W. T., Opthof, T., and Coronel, R. (2007). Dietary fish oil diet reduces the incidence of triggered arrhythmias in pig ventricular myocytes. Heart Rhythm 4, 1452-1460.

Bookstein, C., Musch, M. W., Dudeja, P. T. A., Rao, M. C., and Chang, E. B. (1997). Inverse relationship between membrane lipid fluidity and activity of $\mathrm{Na}^{+} / \mathrm{H}^{+}$exchangers, NHE1 and NHE3, in transfected fibroblasts. $J$. Membr. Biol. 160, 183-192.

Boyarsky, G., Ganz, M. B., Sterzel, R. B., and Boron, W. F. (1988). pH regulation in single glomerular mesangial cells. I. Acid extrusion in absence and presence of HCO3-. Am. J. Physiol. 255, C844-C856.

Burr, M. L., Gilbert, J. F., Holliday, R. M., Elwood, P. C., Fehily, A. M., Rogers, S., Sweetnam, P. M., and Deadman, erk, A. O., Schumacher, C. A., K., McSwine, R. L., Xie, Y., Brasitus,

\section{CONCLUSION}

Dietary $\omega 3$-PUFAs from FO suppress upregulation of the NHE-1 activity in a rabbit model of volume- and pressure-overload. The degree of hypertrophy and HF is similar in myocytes of $\omega 3$-PUFAs and $\omega 9$-MUFAs fed HF rabbits, but the lower NHE-1 activity in myocytes of $\omega 3$-PUFAs fed HF rabbits suggests that dietary $\omega 3$-PUFAs administration during the development of HF may be anti-arrhythmic via reduction of ischemia/reperfusion injury and $\mathrm{Ca}^{2+}$-modulated arrhythmias.

\section{ACKNOWLEDGMENTS}

The authors thank Charly Belterman, Cees Schumacher, and Berend de Jonge for their excellent technical assistance. This work was supported by grants from the Netherlands Heart Foundation (2003B079 and 2007B019).

N. M. (1989). Effects of changes in fat, fish, and fibre intakes on death and myocardial reinfarction: diet and reinfarction trial (DART). Lancet 334, 757-761.

Camillión de Hurtado, M. C., Portiansky, E. L., Pérez, N. G., Rebolledo, O. R., and Cingolani, H. E. (2002). Regression of cardiomyocyte hypertrophy in SHR following chronic inhibition of the $\mathrm{Na}^{+} / \mathrm{H}^{+}$exchanger. Cardiovasc. Res. 53, 862-868.

Chahine, M., Bkaily, G., Nader, M., Al-Khoury, J., Jacques, D., Beier, N., and Scholz, W. (2005). NHE1-dependent intracellular sodium overload in hypertrophic hereditary cardiomyopathy: prevention by NHE-1 inhibitor. J. Mol. Cell. Cardiol. 38, 571-582.

Chen, J., Shearer, G. C., Chen, Q., Healy, C. L., Beyer, A. J., Nareddy, V. B., Gerdes, A. M., Harris, W. S., O'Connell, T. D., and Wang, D. (2011). Omega-3 fatty acids prevent pressure overload-induced cardiac fibrosis through activation of cyclic GMP/protein kinase G signaling in cardiac fibroblasts. Circulation 123, 584-593.

Chen, L., Chen, C. X., Can, X. T., Beier, N., Scolz, W., and Karmazyn, M. (2004). Inhibition and reversal of myocardial infarction-induced hypertrophy and heart failure by NHE-1 inhibition. Am. J. Physiol. 286, H381-H387.

Cingolani, H. E., and Ennis, I. L. (2007). Sodium-hydrogen exchanger, cardiac overload, and myocardial hypertrophy. Circulation 115, 1090-1100.

de Groot, J. R., Schumacher, C. A., Verkerk, A. O., Baartscheer, A., Fiolet, J. W. T., and Coronel, R. (2003). Intrinsic heterogeneity in repolarization is increased in isolated failing rabbit cardiomyocytes during simulated ischemia. Cardiovasc. Res. 59, 705-714.

den Ruijter, H. M., Berecki, G., Opthof, T., Verkerk, A. O., Zock, P. L., and Coronel, R. (2007). Pro- and antiarrhythmic properties of a diet rich in fish oil. Cardiovasc. Res. 73, 316-325. den Ruijter, H. M., Berecki, G., Verkerk, A. O., Bakker, D., Baartscheer, A., Schumacher, C. A., Belterman, C. N. W., de Jonge, N., Fiolet, J. W. T., Brouwer, I. A., and Coronel, R. (2008). Acute administration of fish oil inhibits triggered activity in isolated myocytes from rabbits and patients with heart failure. Circulation 117, 536-544.

den Ruijter, H. M., Verkerk, A. O., Berecki, G., Bakker, D., van Ginneken, A. C. G., and Coronel, R. (2006). Dietary fish oil reduces the occurrence of early afterdepolarizations in pig ventricular myocytes. $J$. Mol. Cell. Cardiol. 41, 914-917.

den Ruijter, H. M., Verkerk, A. O., and Coronel, R. (2010). Incorporated fish oil fatty acids prevent action potential shortening induced by circulating fish oil fatty acids. Front. Physiol. 1:149. doi:10.3389/fphys.2010.00149

Díaz, R. G., Nolly, M. B., Massarutti, C., Casarini, M. J., Garciarena, C. D., Ennis, I. L., Cingolani, H. E., and Pérez, N. G. (2010). Phosphodiesterase $5 \mathrm{~A}$ inhibition decreases NHE-1 activity without altering steady state pHi: role of phosphatases. Cell. Physiol. Biochem. 26, 531-540.

Duda, M. K., O’Shea, K. M., Lei, B., Barrows, B. R., Azimzadeh, A. M., McElfresh, T. E., Hoit, B. D., Kop, W. J., and Stanley, W. C. (2007). Dietary supplementation with $\omega 3$ PUFA increases adiponectin and attenuates ventricular remodeling and dysfunction with pressure overload. Cardiovasc. Res. 76, 303-310. 
Engelhardt, S., Hein, L., Keller, U., Klämbt, K., and Lohse, M. J. (2002). Inhibition of $\mathrm{Na}^{+}-\mathrm{H}^{+}$exchange prevents hypertrophy, fibrosis, and heart failure in $\beta 1$-adrenergic receptor transgenic mice. Circ. Res. 90, 814-819.

Fliegel, L. (2009). Regulation of the $\mathrm{Na}^{+} / \mathrm{H}^{+}$exchanger in the healthy and diseased myocardium. Expert Opin. Ther. Targets 1, 55-68.

Fliegel, L., and Karmazyn, M. (2004). The cardiac Na-H exchanger: a key downstream mediator for the cellular hypertrophic effects of paracrine, autocrine and hormonal factors. Biochem. Cell Biol. 82, 626-635.

Folch, J., Lees, M., and Stanley, G. H. S. (1957). A simple method for the isolation and purification of total lipids from animal tissues. J. Biol. Chem. 226, 497-509.

GISSI-Prevenzione Investigators. (1999). Dietary supplementation with $n-3$ polyunsaturated fatty acids and vitamin $\mathrm{E}$ after myocardial infarction: results of the GISSIPrevenzione trial. Lancet 354, 447-455.

Goel, D. P., Maddaford, T. G., and Pierce, G. N. (2002). Effects of $\omega-3$ polyunsaturated fatty acids on cardiac sarcolemmal $\mathrm{Na}^{+} / \mathrm{H}^{+}$exchange. Am. J. Physiol. Heart Circ. Physiol. 283, H1688-H1694.

Jahangiri, A., Leifert, W. R., Patten, G. S., and McMurchie, E. J. (2000). Termination of asynchronous contractile activity in rat atrial myocytes by $\mathrm{n}$ 3 polyunsaturated fatty acids. Mol. Cell. Biochem. 206, 33-41.

Janse, M. J. (2004). Electrophysiological changes in heart failure and their relationship to arrhythmogenesis. Cardiovasc. Res. 61, 208-217.

Kandasamy, R. A., Yu, F. H., Harris, R., Boucher, A., Hanrahan, J. W., and Orlowski, J. (1995). Plasma membrane $\mathrm{Na}^{+} / \mathrm{H}^{+}$exchanger isoforms (NHE-1, -2, and -3) are differentially responsive to second messenger agonists of the protein kinase A and C pathways. J. Biol. Chem. 270, 29209-29216.

Karmazyn, M., Sostaric, J. V., and Gan, X. T. (2001). The myocardial of $\mathrm{Na}^{+} / \mathrm{H}^{+}$exchanger: a potential therapeutic target for the prevention of myocardial ischaemic and reperfusion injury and attenuation of postinfarction heart failure. Drugs 61,375-389.

Kris-Etherton, P. M., Harris, H. S., and Appel, L. J. (2002). Fish consumption, fish oil, omega-3 fatty acids, and cardiovascular disease. Circulation 106, 2747-2757.
Lee, B. H., Yi, K. Y., Lee, S., Lee, S., and Yoo, S. E. (2005). Effects of KR-32570, a new sodium hydrogen exchanger inhibitor, on myocardial infarction and arrhythmias induced by ischemia and reperfusion. Eur. J. Pharmacol. 523, 101-108.

Levitan, E. B., Wolk, A., and Mittleman, M. A. (2009). Fish consumption, marine omega- 3 fatty acids, and incidence of heart failure: a population-based prospective study of middle-aged and elderly men. Eur. Heart J. 30, 1495-1500.

London, B., Albert, C., Anderson, M. E., Giles, W. R., Van Wagoner, D. R., Balk, E., Billman, G. E., Chung, M., Lands, W., Leaf, A., McAnulty, J., Martens, J. R., Costello, R. B., and Lathrop, D. A. (2007). Omega-3 fatty acids and cardiac arrhythmias: prior studies and recommendations for future research: a report from the National Heart, Lung, and Blood Institute and Office Of Dietary Supplements Omega-3 Fatty Acids and their Role in Cardiac Arrhythmogenesis Workshop. Circulation 116, e320-e335.

Marx, S. O., Reiken, S., Hisamatsu, Y., Jayaraman, T., Burkhoff, D., Rosemblit, N., and Marks, A. R. (2000). PKA phosphorylation dissociates FKBP12.6 from the calcium release channel (ryanodine receptor): defective regulation in failing hearts. Cell 101, 365-376.

Mohan, I. K., and Das, U. N. (2001). Effect of L-arginine-nitric oxide system on the metabolism of essential fatty acids in chemical induced diabetes mellitus in experimental animals by polyunsaturated fatty acids. Nutrition 17, 126-151.

Mozaffarian, D., Bryson, C. L., Lemaitre, R. N., Burke, G. L., and Siscovick, D. S. (2005). Fish intake and risk of incident heart failure. J. Am. Coll. Cardiol. 45, 2015-2021.

Nakamura, T. Y., Iwata, Y., Arai, Y., Komamura, K., and Wakabayashi, S. (2008). Activation of $\mathrm{Na}^{+} / \mathrm{H}^{+}$ exchanger 1 is sufficient to generate $\mathrm{Ca}^{2+}$ signals that induce cardiac hypertrophy and heart failure. Circ. Res. 103, 891-899.

Niizeki, T., Takeishi, Y., Kitahara, T., Arimoto, T., Ishino, M., Bilim, O., Suzuki, S., Sasaki, T., Nakajima, O., Walsh, R. A., Goto, K., and Kubota, I. (2008). Diacylglycerol kinase$\varepsilon$ restores cardiac dysfunction under chronic pressure overload: a new specific regulator of $\mathrm{G} \alpha_{\mathrm{q}}$ signaling cascade. Am. J. Physiol. Heart Circ. Physiol. 295, H245-H255.
Nuss, H. B., Kääb, S., Kass, D. A. Tomaselli, G. F., and Marbán, E. (1999). Cellular basis of ventricular arrhythmias and abnormal automaticity in heart failure. Am. J. Physiol. 277, H80-H91.

Ogawa, A., Suzuki, Y., Aoyama, T., and Takeuchi, H. (2009). Dietary alphalinolenic acid inhibits angiotensinconverting enzyme activity and mRNA expression levels in the aorta of spontaneously hypertensive rats. J. Oleo Sci. 58, 355-360.

Onohara, N., Nishida, M., Inoue, R., Kobayashi, H., Sumimoto, H., Sato, Y., Mori, Y., Nagao, T., and Kurose, H. (2006). TRPC3 and TRPC6 are essential for angiotensin II-induced cardiac hypertrophy. EMBO J. 25, 5305-5316.

Owen, A. J., Peter-Przyborowska, B. A., Hoy, A. J., and McLennan, P. L. (2004). Dietary fish oil doseand time-response effects on cardiac phospholipid fatty acid composition. Lipids 39, 955-961.

Pogwizd, S. M., and Bers, D. M. (2004). Cellular basis of triggered arrhythmias in heart failure. Trends Cardiovasc. Med. 14, 61-66.

Ramadeen, A., Laurent, G., dos Santos, C. C., Hu, X., Connelly, K. A., Holub, B. J., Mangat, I., and Dorian, P. (2010). n-3 Polyunsaturated fatty acids alter expression of fibrotic and hypertrophic genes in a dog model of atrial cardiomyopathy. Heart Rhythm 7, 520-528.

Roos, A., and Boron, W. F. (1981). Intracellular pH. Physiol. Rev. 61, 296-434.

Sartori, M., Ceolotto, G., and Semplicini, A. (1999). MAP Kinase and regulation of the sodium-proton exchanger in human red blood cell. Biochim. Biophys. Acta 1421, 140-148.

Seung-Kim, H. F., Weeber, E. J., Sweatt, J. D., Stoll, A. L., and Marangell, L. B. (2001). Inhibitory effects of omega3 fatty acids on protein kinase C activity in vitro. Mol. Psychiatry 6, 246-248.

Sipido, K. R., Volders, P. G., de Groot, S. H., Verdonck, F., Van de Werf, F., Wellens, H. J., and Vos, M. A. (2000). Enhanced $\mathrm{Ca}^{+}{ }^{+}$release and $\mathrm{Na} / \mathrm{Ca}$ exchange activity in hypertrophied canine ventricular myocytes: potential link between contractile adaptation and arrhythmogenesis. Circulation 102, 2137-2144.

Takahashi, R., Okumura, K., Asai, T., Hirai, T., Murakami, H., Murakami, R., Numaguchi, Y., Matsui, H., Ito, M., and Murohara, T. (2005).
Dietary fish oil attenuates cardiac hypertrophy in lipotoxic cardiomyopathy due to systemic carnitine deficiency. Cardiovasc. Res. 68 213-223.

van Borren, M. M. G. J., Baartscheer, A., Wilders, R., and Ravesloot, J. H. (2004). NHE-1 and NBC during pseudo-ischemia/reperfusion in rabbit ventricular myocytes. J. Mol. Cell. Cardiol. 37, 567-577.

van Borren, M. M. G. J., Zegers, J. G., Baartscheer, A., and Ravesloot, J. H. (2006). Contribution of NHE-1 to cell length shortening of normal and failing rabbit cardiac myocytes. J. Mol. Cell. Cardiol. 41, 706-715.

Vaughan-Jones, R. D., Spitzer, K. W., and Swietach, P. (2009). Intracellular $\mathrm{pH}$ regulation in heart. J. Mol. Cell. Cardiol. 46, 318-331.

Verkerk, A. O., den Ruijter, H. M., Bourier, J., Boukens, B. J., Brouwer, I. A., Wilders, R., and Coronel, R. (2009). Dietary fish oil reduces pacemaker current and heart rate in rabbit. Heart Rhythm 6, 1485-1492.

Verkerk, A. O., Tan, H. L., and Ravesloot, J. H. (2004). Ca2 ${ }^{+}$-activated $\mathrm{Cl}^{-}$current reduces transmural electrical heterogeneity within the rabbit left ventricle. Acta Physiol. Scand. 180, 239-247.

Verkerk, A. O., van Ginneken, A. C. G., Berecki, G., den Ruijter, H. M., Schumacher, C. A., Veldkamp, M.W., Baartscheer, A., Casini, S., Opthof, T., Hovenier, R., Fiolet, J. W. T., Zock, P. L., and Coronel, R. (2006). Incorporated sarcolemmal fish oil fatty acids shorten pig ventricular action potentials. Cardiovasc. Res. 70, 509-520.

Verkerk, A. O., van Ginneken, A. C. G., van Veen, T. A. B., and Tan, H. L. (2007). Effects of heart failure on brain-type $\mathrm{Na}^{+}$channels in rabbit ventricular myocytes. Europace 9, 571-577.

Verkerk, A. O., Veldkamp, M. W., Bouman, L. N., and van Ginneken, A. C. G. (2000a). Calcium-activated $\mathrm{Cl}^{-}$current contributes to delayed afterdepolarizations in single Purkinje and ventricular myocytes. Circulation 101, 2639-2644.

Verkerk, A. O., Veldkamp, M. W., de Jonge, N., Wilders, R., and van Ginneken, A. C. G. (2000b). Injury current modulates afterdepolarizations in single human ventricular cells. Cardiovasc. Res. 47, 124-132.

Vermeulen, J. T., McGuire, M. A., Opthof, T., Coronel, R., de Bakker, J. M. T., Klöpping, C., and Janse, M. J.(1994). Triggered activity and 
automaticity in ventricular trabeculae of failing human and rabbit hearts. Cardiovasc. Res. 28, 1547-1554.

Yamagishi, K., Iso, H., Date, C., Fukui, M., Wakai, K., Kikuchi, S., Inaba, Y., Tanabe, N., and Tamakoshi, A. (2008). Fish, $\omega-3$ polyunsaturated fatty acids, and mortality from cardiovascular diseases in a nationwide community-based cohort of Japanese men and women: the
JACC (Japan Collaborative Cohort Study for evaluation of cancer risk) study. J. Am. Coll. Cardiol. 52, 988-996.

Conflict of Interest Statement: The authors declare that the research was conducted in the absence of any commercial or financial relationships that could be construed as a potential conflict of interest.
Received: 26 September 2011; accepted: 15 March 2012; published online: 02 April 2012.

Citation: van Borren MMGJ, den Ruijter HM, Baartscheer A, Ravesloot JH, Coronel $R$ and Verkerk $A O$ (2012) Dietary omega-3 polyunsaturated fatty acids suppress NHE-1 upregulation in a rabbit model of volume- and pressureoverload. Front. Physio. 3:76. doi: 10.3389/fphys.2012. 00076
This article was submitted to Frontiers in Cardiac Electrophysiology, a specialty of Frontiers in Physiology.

Copyright (C) 2012 van Borren, den Ruijter, Baartscheer, Ravesloot, Coronel and Verkerk. This is an open-access article distributed under the terms of the Creative Commons Attribution Non Commercial License, which permits noncommercial use, distribution, and reproduction in other forums, provided the original authors and source are credited. 